\title{
Review
}

\section{Embryonic stem cell application in drug discovery}

\author{
Yi-jia LOU*, Xing-guang LIANG \\ Institute of Pharmacology, Toxicology and Biochemical Pharmaceutics, Zhejiang University, Hangzhou 310058, China
}

Embryonic stem (ES) cells and their differentiated progeny offer tremendous potential for regenerative medicine, even in the field of drug discovery. There is an urgent need for clinically relevant assays that make use of ES cells because of their rich biological utility. Attention has been focused on small molecules that allow the precise manipulation of cells in vitro, which could allow researchers to obtain homogeneous cell types for cell-based therapies and discover drugs for stimulating the regeneration of endogenous cells. Such therapeutics can act on target cells or their niches in vivo to promote cell survival, proliferation, differentiation, and homing. In the present paper, we reviewed the use of ES cell models for high-throughput/content drug screening and toxicity assessment. In addition, we examined the role of stem cells in large pharmaceutical companies' R\&D and discussed a novel subject, nicheology, in stem cellrelated research fields.

Keywords: embryonic stem cells; induced pluripotent stem (iPS) cells; differentiation; small molecules; high-throughput/content screening; drug discovery; toxicity assessment; nicheology

Acta Pharmacologica Sinica (2011) 32: 152-159; doi: 10.1038/aps.2010.194; published online 10 Jan 2011

\section{Introduction}

Stem cell research promises to make significant progress in regenerative medicine to replace damaged tissues and organs. An outstanding landmark in the past decade has been the development between stem cell biology and chemistry ${ }^{[1-6]}$. The combination of the two fields will likely provide an impetus for revealing intricate molecular interactions and functions under complex cellular differentiation, which offers systems for drug discovery and sources for potential cell therapy ${ }^{[7-10]}$.

Embryonic stem (ES) cells can mimic embryogenesis and differentiate into cells of the three embryonic germ layers (endoderm, mesoderm, and ectoderm) from which various specialized cell types of the entire organism are produced ${ }^{[11]}$. Human ES (hES) cells can also differentiate into all terminal cell types of the human body. Small molecules with inducing ability in vitro are expected to possess their own mechanism of promoting differentiation in vivo. This makes them potentially valuable for pharmaceutical development and safety assessment. Indeed, small molecules can be screened using hES cell models to find new chemical entities that modulate the fate of adult stem cells, or they could be used directly in cell therapies $^{[4,8,10,11]}$.

Mouse ES (mES) cells have been in use for several years in drug discovery to develop genetically modified mice for target

\footnotetext{
* To whom correspondence should be addressed. E-mail yijialou@zju.edu.cn

Received 2010-06-10 Accepted 2010-10-12
}

validation, target selectivity, model development and toxicity evaluation $^{[12-17]}$. Combined with advances in hES cell technology, the drug discovery community may soon have a physiologically relevant screening tool (with limitless availability) that shows normal growth and genetic structure.

Understanding molecular mechanisms that determine stem cell fate (ie, self-renewal or differentiation) will significantly promote the realization of the therapeutic potential of stem cells $^{[16,18-22]}$. To date, much attention has been paid to signal transduction and the related molecular events during ES cell differentiation. ES cells probably had some novel drug targets, especially in a definite differentiation medium containing lowmolecular-weight compound(s). Studies have suggested that a stem cell niche is dynamic, not static, and can be modified or even created ${ }^{[23-27]}$. Therefore, the stem cell niches regulated by small molecules can control the cell fate, which offers a suitable microenvironment to screen drugs.

A chemical approach of differentiation by small molecules has currently been developed. This review will address ES cell lines that could potentially be used to discover low-molecular-weight agents for the control of differentiation and drugs for the treatment of degenerative diseases. In addition, small molecules could participate in producing induced pluripotent stem (iPS) cells for lower oncogenic and higher reprogramming efficiency by small-molecule hitting.

ES cell models for drug screening

The development of new drugs is costly and time-consuming. 
In particular, the initial stages of research and development (R\&D) require in vitro models to screen the activity and toxicity of a large number of compounds. Thus, a suitable model that can be used for both effects and safety assessment is extremely important. Cell-based in vitro assays with high human relevance are urgently needed for pre-clinical activities. Previous studies have suggested that ES cells could serve as a screening platform to identify low-molecular-weight compounds that affect endogenous stem cell populations and repair damaged tissue $^{[4,8,10,11,28,29]}$, and a set of screening protocols is available (ie, the primary screen and the secondary assay). In addition, several cell lines, such as D3 mES cells and H1, H7, and H9 hES cells, are available for drug screening ${ }^{[12,30,31]}$. Table 1 lists some characteristics of ES cell and other cell types and their respective advantages and disadvantages.

\section{High-throughput/content screening (primary screen)}

Small-molecule libraries can contain millions of compounds. Thus, screens must be employed to effectively eliminate molecules that are toxic or do not have any biological activity. High-throughput screening (HTS) technologies already allow the rapid testing of thousands of compounds. Studies have suggested, however, that screening against a defined molecular target usually exploits a protein's function and results in expression or transcription of differentiation-related genes $^{[29,32,33]}$. For instance, HTS assays usually use 96- or 384well plates, and the assays can be performed on chemical compounds in various formats.

Generally, enzymatic activity, signal transduction, or molecular interactions with partners that contain reporter systems have been used to assess whether compounds activate par- ticular signaling pathways of interest ${ }^{[34]}$. Recently, a notable report demonstrated an image-based, high-content assay for detecting compounds that affect hES cell survival or pluripotency ${ }^{[35]}$. In that study, 1040 compounds were screened using an hES cell colony-based assay. The assay was designed to detect changes in the phenotype of hES cell colonies by quantifying multiple parameters, including the number of cells in a colony, colony area and shape, intensity of nuclear staining, the percentage of cells in the colony that expressed a marker of pluripotency, and the number of colonies per well. As a result, several steroids that promoted hES cell differentiation were identified, and the antihypertensive drug pinacidil was shown to affect hES cell survival. Phenotypic screens can be advantageous because they can be carried out in cells by examining multiple markers and functional changes (for example, cell morphology and behavior) using automated high-content imaging technologies in a high-throughput manner ${ }^{[1,4,36,37]}$.

HTS based on receptors in ES cell-derived neurons have also been reported ${ }^{[38]}$. That study described an mES cell-based screen of a library of $2.4 \times 10^{6}$ compounds, as well as the identification of novel chemical "hits" for alpha-amino-3-hydroxyl5-methyl-4-isoxazolepropionate-subtype glutamate receptors, structure-function relationships of compounds and receptors, and validation of lead compounds. The emergence of automated cellular systems has allowed rapid visualization of large groups of cells and phenotypic analysis in a quantitative manner.

Primary screens can also be directly evaluated under a contrast-phase microscope to examine cell differentiation into terminal cells. One protocol for hES cell differentiation into neuroepithelial cells has been recommended, and evaluation

Table 1. Advantages and disadvantages of different cells available for drug screening.

\begin{tabular}{|c|c|c|}
\hline Cell types & Advantages & Disadvantages \\
\hline Immortalized & - Homogeneous cell population & - Lack important aspects of native function \\
\hline cell lines & $\begin{array}{l}\text { - Growth and maintenance cheap } \\
\text { - Time- and labor-saving }\end{array}$ & $\begin{array}{l}\text { - Genetic mutations that cause permanent and heritable } \\
\text { change in the phenotype }\end{array}$ \\
\hline Primary cells & $\begin{array}{l}\text { - Close approximation of native function } \\
\text { - Reflect in vivo physiological or pathological condition }\end{array}$ & $\begin{array}{l}\text { - Require fresh preparation } \\
\text { - Difficult to procure in sufficient quantity } \\
\text { - prone to batch-to-batch variability in quality }\end{array}$ \\
\hline \multirow[t]{2}{*}{ Stem cells } & $\begin{array}{l}\text { - Continuously propagated in vitro and retain the } \\
\text { potential to generate all the cell types of the body } \\
\text { (ES cell). }\end{array}$ & $\begin{array}{l}\text { - Limited potential for expansion and are lineage restricted } \\
\text { (adult stem cells), } \\
\text { - Growth and maintenance expensive }\end{array}$ \\
\hline & $\begin{array}{l}\text { - Compounds can modulate more than one target to } \\
\text { achieve a desired biological effect. } \\
\text { - High quantity } \\
\text { - Readily available source of all cell types } \\
\text { - Both develop-dependent and fully differentiated cell } \\
\text { types }\end{array}$ & $\begin{array}{l}\text { - A lot of time needed to obtain } \\
\text { fully differentiated cell types } \\
\text { - Require more effort to achieve } \\
\text { purified populations }\end{array}$ \\
\hline \multirow[t]{4}{*}{ iPS cells } & - With genetic information of the patients & $\begin{array}{l}\text { - Very low efficacy for harvest, ( } \leq 1 \%) \text {, expensive for } \\
\text { preparations, }\end{array}$ \\
\hline & - Reflect in vivo physiological or pathological condition & - Growth and maintenance expensive \\
\hline & $\begin{array}{l}\text { - Mimic both develop-dependent and fully differentiated } \\
\text { cell types }\end{array}$ & $\begin{array}{l}\text { - A lot of time needed to obtain fully differentiated } \\
\text { cell types }\end{array}$ \\
\hline & & - Require more effort to achieve purified populations \\
\hline
\end{tabular}


under a contrast-phase microscope has been described ${ }^{[39]}$. Recent studies in hES cells have identified a novel neural stem cell stage (ie, the rosette stage). In this stage, cells exhibit plasticity by generating a broad range of neuronal cell types in response to appropriate developmental signals. Such rosettestage neural stem cells can also be distinguished from other neural stem cell populations with a contrast-phase microscope because of their specific rosette cytoarchitecture ("morphology" $)^{[40]}$. The striking cytoarchitecture of rosettes could become a powerful tool for translational medicine and applications in HTC assays that require large numbers of homogeneous cell populations. Recently, a study reported that light microscopy could be used to evaluate embryoid body (EB) structure and size, and the number of wells containing contracting cardiomyocytes was determined ${ }^{[41]}$. In addition, hepatocytes containing two morphologically distinct populations, a mononuclear population and a binuclear population, were clearly identified under light microscopy. Another study used immunohistochemical analysis to confirm that albuminpositive cells (ie, hepatocytes) were present in the outgrowths of EBs with binuclear cells ${ }^{[42]}$. Examining differentiation into terminal cells under a contrast-phase microscope can save both time and labor during a primary screen. Indeed, this approach has been shown to be helpful for successful screening $^{[14]}$.

More recently, a screen for chemical mediators of reprogramming has been reported ${ }^{[39]}$. So far, most studies of direct reprogramming have been performed with lentiviruses/retroviruses, which encode the reprogramming factors. This represents a major limitation to therapeutic applications because viral integration in the host genome increases the risk of tumorigenicity. Low-level residual expression of reprogramming factors may alter the differentiation potential of human induced pluripotent stem (iPS) cells. Indeed, both the viral vectors used for gene transfer and the encoded reprogramming factors are probably oncogenic and possess low transduction efficiency ${ }^{[43]}$. Some small molecules can replace transcription factors, and the combined activity of transcription factors can reprogram adult cells into iPS cells. For example, one study using a high-throughput/content screen showed that a TGF- $\beta$ inhibitor replaced Sox 2 in reprogramming and produced unmodified iPS cell lines ${ }^{[44]}$. Therefore, small-molecule replacement of transcription factors may be one potential solution to lower the oncogenic potential and increase the reprogramming efficiency ${ }^{[39,43,44]}$.

Another valuable report demonstrated a strategy to adapt hES cells to HTS conditions, which resulted in an assay that is suitable for the discovery of small molecules that drive the self-renewal or differentiation of hES cells ${ }^{[45]}$. Use of this new assay (ie, global gene expression analysis) has led to the identification of several marketed drugs and natural compounds that promote short-term hES cell maintenance and direct early lineage choice during differentiation. Desbordes et al demonstrated the feasibility of hES cell-based HTS and enhanced the repertoire of chemical compounds that can manipulate hES cell fate.

\section{A series of secondary assays}

It has also been recommended that, in general, hit compounds identified from a primary screen be further confirmed using a series of more functional secondary assays and analyzed using informatics tools ${ }^{[29,45,46]}$. Before a compound enters mechanistic studies, it is normally optimized through structure-activity relationship studies to improve its properties, such as increasing its potency and specificity and enhancing its pharmacokinetic properties. All these data can be expected to be obtained via secondary assays.

To identify the molecular targets and pathways of an unknown compound, biochemical and cellular or sub-cellular experiments are commonly used. One study reported that phosphoserine (P-Ser) increased neurogenesis in hES cellderived neural progenitors ${ }^{[1]}$. It also confirmed that the effects of P-Ser are mediated by the group III metabotropic glutamate receptor 4 (mGluR4). Saxe and colleagues highlighted the tremendous potential of developing effective small-molecule drugs for use in regenerative medicine or transplantation therapy.

Similarly, protein interactions can be mapped in ES cells to enable systematic discovery of regulatory pathways ${ }^{[47,48]}$. Indeed, a method for defining the proteome of stem cell populations using isobaric tags for relative and absolute quantitation has been developed. This allows simultaneous analysis of samples to be analyzed simultaneously, which can give relative quantification for hundreds of proteins from a relatively small (1-5 million) cell number. It is a rapid secondary assay system that precedes more-focused, hypothesis-driven research. The available techniques to study translational regulation of protein levels have decreased the reliance on proteomic confirmation of mRNA-based analyses. In addition, these techniques offer opportunities to develop new quantitative biological approaches to investigate stem cell self-renewal or differentiation, which increase the probability of discovering proteins that regulate development.

During the early stage of development, differentiationrelated gene expression or transcriptomics can be regulated, and a genome-wide transcriptional analysis has been used as a powerful assay ${ }^{[32,33,49]}$. For example, genome-wide transcriptional analysis has shown more than just the effects of Mesp 1 dramatically accelerates and enhances multipotent cardiovascular progenitor specification through an intrinsic and cellautonomous mechanism. In addition, analysis at various time points identified 1355 genes that were significantly regulated, and the differentiation track was described in a principal component analysis ${ }^{[33]}$. Differentiation cultures exposed to monobutyl phthalate or 6-aminonicotinamide (from the EB stage onward) for 24 or $96 \mathrm{~h}$ showed RNA expression patterns that deviated from the differentiation track. Studies like these demonstrate that secondary assays can be used as informatics tools and are involved in further functional evaluation.

ES cell models for drug toxicity assessment 
Stem cells have been used to evaluate cardiotoxicity for more than 10 years. ES cells are an important in vitro model to test drugs, and they have the potential to predict toxicity in human ${ }^{[32,33,50]}$. For example, a stem cell-based reporter assay was developed to detect drug-induced alterations in the canonical Wnt/ $\beta$-catenin signaling pathway, which is involved in the regulation of early embryonic development. The so-called ReProGlo assay allows simultaneous determination of cell viability and luciferase reporter activity in a high throughput 96-well microtiter format ${ }^{[50]}$. Several test chemicals were analyzed in the new assay system, and known embryo toxicants like retinoic acid and lithium chloride induced concentration-dependent increases in reporter activity. The potency of valproic acid and a series of structural analogs that activate the Wnt pathway correlated well with their reported teratogenic activity in the mouse. The new test may help to predict embryotoxic potential of chemicals in drug discovery.

Studies have also utilized differentiated fibroblastic progenies of hES cells for in vitro toxicological screening ${ }^{[51]}$. These cells were generated through random spontaneous differentiation within standard culture media over several passages. The cytotoxic response of the differentiated hES cell fibroblastic progenies to mitomycin $\mathrm{C}$ was observed to be more sensitive than the L929 cell line. Therefore, ES cell tests represent reliable, scientifically validated in vitro systems for the detection and classification of compounds according to their teratogenic potency $^{[41,51-57]}$.

Using contrast-phase microscope is a simple way to examine cell differentiation into terminal cells. One study used light microscopy to determine the number of wells containing contracting cardiomyocytes and evaluate EB structure and size $\mathrm{e}^{[41]}$. The results indicated that a decrease in the $\mathrm{pH}$ may be the mechanism by which the alkoxyacetic acid metabolites of glycol ethers cause embryotoxicity. Interestingly, scientists have developed a new molecular approach based on an analysis of the expression of certain marker proteins specific for developing heart tissue ${ }^{[52]}$. The approach involves a combination of quantitative flow cytometry, to measure marker proteins (ie, sarcomeric myosin heavy chain and a-actinin) in mES cells on day 7 , and concurrent cell viability analysis. This approach was subsequently referred to as a molecular fluorescenceactivated cell sorting (FACS)-ES cell test, which offered the same sensitivity as the validated protocol, but did not require as much time. This new molecular method has the potential to be a sensitive, rapid and reproducible screening tool, which is highly suited to predict developmental toxicity in vivo from in vitro data. This protocol was also suitable for in vitro embryotoxicity assays by measuring the disturbance of the differentiation of ES cells into endothelial cells (ie, the reduction in the expression of platelet/endothelial cell adhesion molecule-1, ie PECAM-1 and vascular endothelial cadherin) ${ }^{[53]}$. Highcontent image analysis was used to assess the utility of dissociated humen N2TM (HN2TM) cultures as an in vitro model for neurite outgrowth ${ }^{[54]}$. In addition, the molecular phenotype of these cells was examined using immunocytochemical staining. The hN2TM cultures are amenable for examining morphological changes and effects on neural outgrowth in high-to-medium-throughput developmental neurotoxicity screening because they possess cellular homogeneity, a rapid rate of neurite outgrowth, and low inter-experiment variability in automated morphological counting by FACS ${ }^{[54,55]}$. The hepatocyte-like cells derived by analysis of the expression of certain marker proteins specific for development method may prove to be useful as an in vitro model of hepatotoxicity ${ }^{[14]}$, which would provide a novel and promising alternative for obtaining large numbers of functional hepatocyte-like cells for in vitro drug metabolism and hepatotoxicity screening of potential drug candidates ${ }^{[56]}$.

The applications of extracellular matrix are relevant to the evaluation of drug efficacy and drug toxicity. To promote both in vitro and in vivo growth, healthy cellularized 3-D tissues are summarized as follows. Primary cells and cell lines, including ES cells constitute a new 3-D method for rapid evaluation of hepatotoxicity in vitro ${ }^{[57]}$. In addition to addressing the roles and advantages of ES cells in the aforementioned toxicity models, this review also examined how genetic selection has been employed to overcome major limitations to the implementation of stem cell-based in vitro models for toxicology.

\section{ES cells with novel drug targets result in "hits" by small- molecular probes}

ES cell differentiation, which involves modulation of the transcription and translation of a vast number of genes and proteins, respectively, offers a desirable model for screening small-molecular probes. This system, which is modeled as a network of regulatory circuits that direct multiple steps of gene expression and mediate spatiotemporal control of a cell's proteome, can determine both cellular phenotype and plasticity ${ }^{[21,27,39,49,58,59]}$. Commitment to developmental lineages has been considered to be a stepwise process. To guide stem cells towards defined fates, researchers will need to know how these changes are regulated so that they can manipulate cells to change in a predictable and reproducible way ${ }^{[60]}$. To address this, it is necessary to identify the molecular target(s) bound by the drug leads, which may be responsible for their pharmacological activity. Direct approaches, such as affinity chromatography, expression cloning and protein microarrays, have analyzed compounds bound to their targets. Indirect approaches are based on a comparison of the genome-wide activity profile of the compound with databases of the activity profiles of other compounds with known targets or activity profiles following specific genetic changes. A variety of technologies and approaches have been explored for target identification after phenotypic screening ${ }^{[1,44,50]}$. Here, we would like to describe our recent work, which took advantage of chemical probing to identify signaling pathways involved in the differentiated state of ES cells (Figure 1). In the schematic drawing, we have reported at least six events initiated by small-molecule compounds (icariin, icaritin, and partly unpublished).

Differentiation is accompanied by a global increase in both transcript levels and efficiency of protein translation. Mul- 
tiple vital genes have been identified where protein levels are exclusively regulated at the translational level during differentiation ${ }^{[13,16,17]}$. For example ${ }^{[1]}$, high-throughput identification of small molecules revealed that the orphan ligand phosphoserine (P-Ser) was an enhancer of neurogenesis. Saxe et al selectively modulated molecular, cellular, and systemlevel properties of the mammalian brain. Phosphoserine has been shown to inhibit neural stem cell/progenitor proliferation and self-renewal, enhance neurogenic fate commitment, and improve neuronal survival. Another group ${ }^{[4]}$ described a chemical screening platform to investigate hES cell differentiation and identified a small molecule, (-)-indolactam $\mathrm{V}$, which specifically works at one stage of pancreatic development to induce pancreatic progenitors from the definitive endoderm. These examples have shown that small molecules that target these regulatory processes are valuable tools for probing and manipulating the molecular mechanisms by which stem cells self-renew, differentiate, and arise from somatic cell reprogramming.

\section{Niche-mediated control of stem cell fate}

Complexity in the spatial organization of ES cell cultures creates heterogeneous microenvironments (niches) that influence ES cell fate. Studies have demonstrated that ${ }^{[23]}$ the rate and trajectory of hES cell differentiation can be controlled by engineering hES cell niche properties. ES cells provide an in vitro system that closely resembles what would occur in vivo ${ }^{[23-26]}$. Significant advances in defining adult stem cell niches and understanding how they regulate stem cell function in vivo have provided new strategies for controlling cell fate (ie, by pharmacologically manipulating the niches). Typically, homogeneous and functional cell types generated

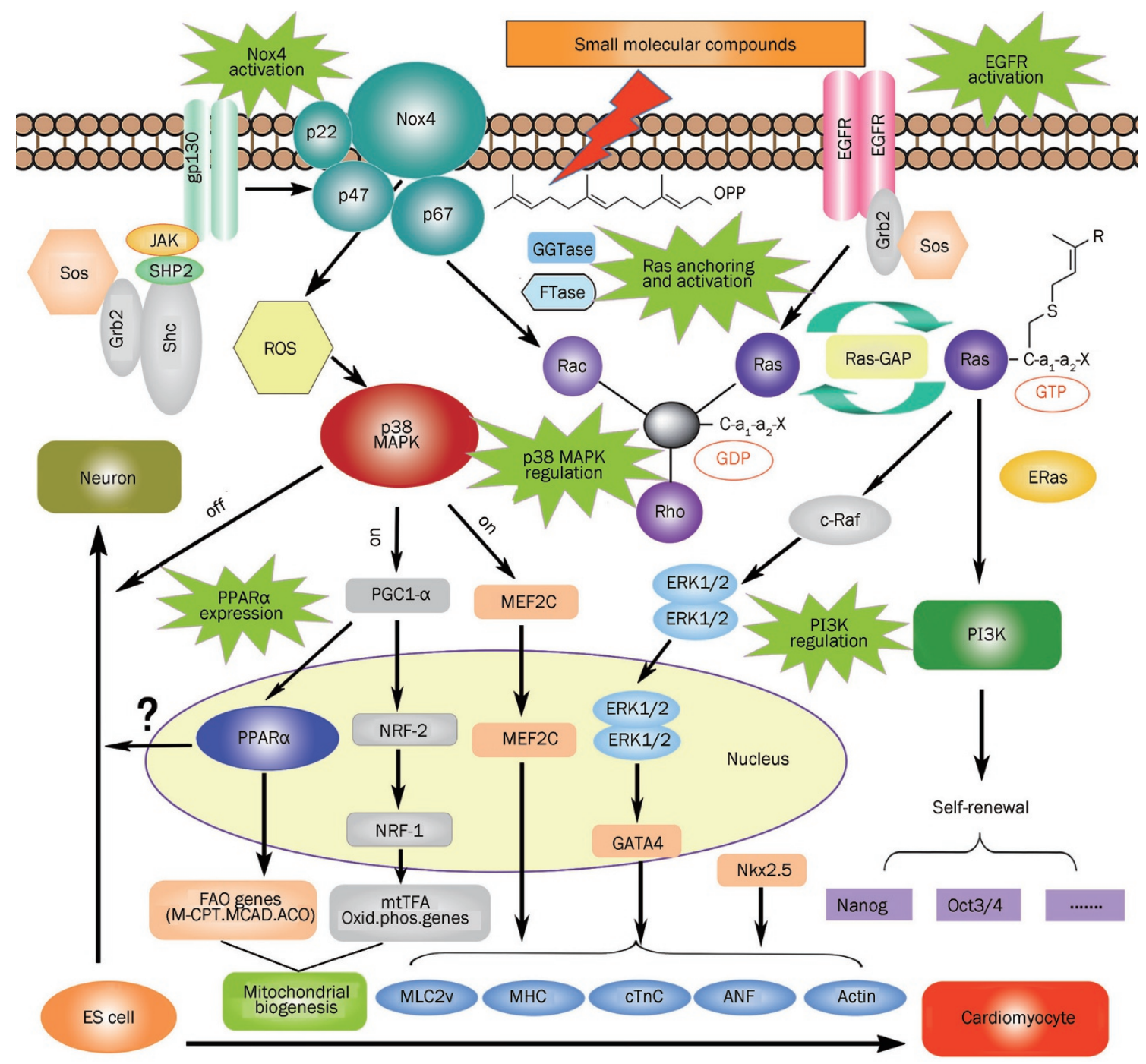

Figure 1. Schematic drawing with proposed mechanisms by which small molecules from a screening library can probe signal transduction and molecular events during stem cell differentiation. The drawing compiles the conclusions of signaling transduction and the possible molecular events. Green stars represent supposed targets for small molecular probe hits. NOX: NADPH oxidases; EGFR:_epidermal growth factor receptor; MAPK: mitogenactivated protein kinase; PPAR: peroxisome proliferator-activated receptor; PI3K: phosphatidylinositol 3-kinase. 
in chemically defined conditions can be used for cell-based therapy. Alternatively, conventional chemical and biological therapeutics can be developed to target patients' own cells or their niches to stimulate regeneration in vivo.

Therefore, the creation of "nicheology" in stem cells is a completely novel concept. Niche originally referred to the maintenance of nearby stem cells in a self-renewing state. Cells without direct contact with the niche were shown to differentiate in vivo ${ }^{[60]}$. The state of stem cell differentiation can be accomplished by supplying outside signals and extracellular factors instead of genetic manipulation ${ }^{[00]}$. The suffix "-ology" is used to describe the study of a specific science subject. Therefore, we defined nicheology as a branch of chemical biology or basic medicine that deals with heterogeneous microenvironments for stem cell fate, regenerative medicine, and drug discovery.

Chemically defined medium conditions for controlling hES cell fate will facilitate the practical application of hES cells in research and therapy. In addition, defined medium conditions will provide an excellent system for studying the molecular mechanisms underlying self-renewal and differentiation without the multiple unknown and variable factors associated with feeder cells and serum. From an in vivo nicheology point of view, these outside signals and the micro-environment constitute a niche in which adult stem cells are present and compete for limiting concentrations of growth factors or drugs, which maintains a balance between self-renewal and differentiation of the cells ${ }^{[23]}$.

\section{Role of stem cells in large pharmaceutical companies}

The development of new drugs is costly and requires a tremendous amount of resources. The large pharmaceutical companies are currently facing increasing developmental costs and a lower success rate of bringing new compounds to the market. Lowering costs and increasing the success rate can be accomplished by increasing the predictability of the candidate drugs in the pipeline and lowering the number of drugs that fail in later stages of testing.

The use of stem cells amongst the top 20 pharmaceutical and top 10 biotech companies was 70\% (64\% with hES cells) and $50 \%$ (20\% with hES cells), respectively ${ }^{[61,62]}$. The screening of small molecules will be the predominate and most exciting approach for developing new therapeutics. The pharmaceutical industry has identified the use of stem cells for drug screening as a new and imminently necessary resource. To date, three European pharmaceutical companies, Roche Holding AG, GlaxoSmithKline and AstraZeneca, have announced that they are starting to develop ways to use stem cells for drug screening.

\section{Prospects}

Although it seems like there are extensive opportunities to use hES cells in combination with HTS systems for elucidation of differentiation pathways, there are essential complexities in these biological systems that need to be taken into consideration. For example, automated high-content analysis can provide information about multiple properties and quantitative data of individual cells, and these analyses are well suited to study non-homogenous cell populations. From a pharmaceutical perspective, the identification of small-molecule compounds regulating cellular differentiation may provide chemical tools that can be translated into clinical applications. Small molecules can replace transcription factors and/or enhance efficiency during somatic cell reprogramming ${ }^{[63]}$. They are also expected to be one potential solution for decreasing the oncogenic potential of iPS cells.

Endogenous adult stem cells exist in multiple tissues throughout the human body. Small molecules with inducing ability in vitro are expected to possess their own promoting differentiation nature in vivo. A novel regenerative medicine approach for tissue repair is focused on direct manipulation of these stem cell pools in situ using drugs from hES cell-based HTS to stimulate regeneration.

\section{Acknowledgements}

This work was supported by the National Natural Science Foundation of China (NSFC № 30973600 and 90813026).

\section{References}

1 Saxe JP, Wu H, Kelly TK, Phelps ME, Sun YE, Kornblum HI, et al. A phenotypic small-molecule screen identifies an orphan ligand-receptor pair that regulates neural stem cell differentiation. Chem Biol 2007; 14: 1019-30.

2 Sharma NS, Wallenstein EJ, Novik E, Maguire T, Schloss R, Yarmush ML. Enrichment of hepatocyte-like cells with upregulated metabolic and differentiated function derived from embryonic stem cells using S-NitrosoAcetyl Penicillamine. Tissue Eng Part C Methods 2009; 15: 297-306.

3 Christie VB, Barnard JH, Batsanov AS, Bridgens CE, Cartmell EB, Collings JC. Synthesis and evaluation of synthetic retinoid derivatives as inducers of stem cell differentiation. Org Biomol Chem 2008; 6: 3497-507.

4 Chen S, Borowiak M, Fox JL, Maehr R, Osafune K, Davidow L, et al. A small molecule that directs differentiation of human ESCs into the pancreatic lineage. Nat Chem Biol 2009; 5: 258-65.

5 Lee J, Wu X, Magliano MP, Peters EC, Wang Y, Hong J, et al. A small-molecule antagonist of the hedgehog signaling pathway. Chembiochem 2007; 8: 1916-9.

6 Wu X, Ding S, Ding Q, Gray NS, Schultz PG. Small molecules that induce cardiomyogenesis in embryonic stem cells. J Am Chem Soc 2004; 126: 1590-1.

7 Chen S, Do JT, Zhang Q, Yao S, Yan F, Peters EC. Self-renewal of embryonic stem cells by a small molecule. Proc Natl Acad Sci USA 2006; 103: 17266-71.

8 Harding SE, Ali NN, Brito-Martins M, Gorelik J. The human embryonic stem cell-derived cardiomyocyte as a pharmacological model. Pharmacol Ther 2007;113: 341-53.

9 Stummann TC, Hareng L, Bremer S. Embryotoxicity hazard assessment of methylmercury and chromium using embryonic stem cells. Toxicology 2007; 242: 130-43.

10 Agarwal S, Holton KL, Lanza R. Efficient differentiation of functional hepatocytes from human embryonic stem cells. Stem Cells 2008; 26 : 1117-27.

11 Klimanskaya I, Rosenthal N, Lanza R. Derive and conquer: sourcing and differentiating stem cells for therapeutic applications. Nat Rev 
Drug Discov 2008; 7: 131-42.

12 Zhu DY, Lou YJ. Inducible effects of icariin, icaritin, and desmethylicaritin on directional differentiation of embryonic stem cells into cardiomyocytes in vitro. Acta Pharm Sin 2005; 26: 477-85.

13 Zhu DY, Lou YJ. Icariin-mediated expression of cardiac genes and modulation of nitric oxide signaling pathway during differentiation of mouse embryonic stem cells into cardiomyocytes in vitro. Acta Pharm Sin 2006; 27: 311-20.

14 Zhu DY, Du Y, Huang X, Guo MY, Ma KF, Lou YJ. et al. MAPEG expression in murine embryonic stem cell-derived hepatic tissue system. Stem cell Dev 2008; 17: 775-84.

15 Hao JJ, Daleo MA, Murphy CK, Yu PB, Ho JN, Hu J, et al. Dorsomorphin, a selective small molecule inhibitor of BMP signaling, promotes cardiomyogenesis in embryonic stem cells. Plos One 2008; 3: 1-8.

16 Ogawa K, Saito A, Matsui H, Suzuki H, Ohtsuka S, Shimosato D, et al. Activin-Nodal signaling is involved in propagation of mouse embryonic stem cells. J Cell Sci 2007; 120: 55-65.

17 Peters AK, Steemans M, Hansen E, Mesens N, Verheyen GR, Vanparys P. Evaluation of the embryotoxic potency of compounds in a newly revised high throughput embryonic stem cell test. Toxicol Sci 2008; 105: 342-50.

18 Elkabetz Y, Panagiotakos G, Shamy GA, Socci ND, Tabar V, Studer L. Human ES cell-derived neural rosettes reveal a functionally distinct early neural stem cell stage. Gene Dev 2008; 22: 152-65.

19 Hakuno D, Takahashi T, Lammerding J, Lee RT. Focal adhesion kinase signaling regulates cardiogenesis of embryonic stem cells. J Biol Chem 2005; 280: 39534-44.

20 Pan G, Thomson JA. Nanog and transcriptional networks in embryonic stem cell pluripotency. Cell Res 2007; 17: 42-9.

21 Sampath P, Pritchard DK, Pabon L, Reinecke H, Schwartz SM, Morris $\mathrm{DR}$, et al. A hierarchical network controls protein translation during murine embryonic stem cell self-renewal and differentiation. Cell Stem Cell 2008; 2: 448-60.

22 Babale Y, Herwig R, Greber B, Brink TC, Wruck W, Groth D, et al. Analysis of Oct4-dependent transcriptional networks regulating selfrenewal and pluripotency in human embryonic stem cells. Stem Cells 2007; 25: 500-10.

23 Peerani R, Rao BM, Bauwens C, Yin T, Wood GA, Nagy A, et al. Nichemediated control of human embryonic stem cell self-renewal and differentiation. EMBO J 2007; 26: 4744-55.

24 Morag H. Stewart MH, Bendall SC, Bhatia M. Deconstructing human embryonic stem cell cultures: niche regulation of self-renewal and pluripotency. J Mol Med 2008; 86: 875-86.

25 Yao S, Chen S, Clark J, Hao E, Beattie GM, Hayek A, et al. Long-term self-renewal and directed differentiation of human embryonic stem cells in chemically defined conditions. Proc Natl Acad Sci USA 2006; 103: 6907-12.

26 Bouhona IA, Kato H, Chandran S, Allen ND. Neural differentiation of mouse embryonic stem cells in chemically defined medium. Brain Res Bull 2005; 68: 62-75.

27 Firestone AJ, Chen JK. Controlling destiny through chemistry: smallmolecule regulators of cell fate. ACS Chem Biol 2010; 5: 15-34.

28 Krencik R, Zhang SC. Stem cell neural differentiation: a model for chemical biology. Curr Opin Chem Biol 2006; 10: 592-7.

$29 \mathrm{Xu} \mathrm{Y,} \mathrm{Shi} \mathrm{Y,} \mathrm{Ding} \mathrm{S.} \mathrm{A} \mathrm{chemical} \mathrm{approach} \mathrm{to} \mathrm{stem-cell} \mathrm{biology} \mathrm{and}$ regenerative medicine. Nature 2008; 453: 338-44.

30 Harding SE, Ali NN, Brito-Martins M, Gorelik J. The human embryonic stem cell-derived cardiomyocyte as a pharmacological model. Pharmacol Ther 2007; 113: 341-53.

31 Brito-Martins M, Harding SE, Ali NN. B1- and 2-adrenoceptor responses in cardiomyocytes derived from human embryonic stem cells: comparison with failing and non-failing adult human heart. $\mathrm{Br} \mathrm{J}$ Pharmacol 2008; 153: 751-9.

32 van Dartel DA, Pennings JL, de la Fonteyne $\amalg$, van Herwijnen MH, van Delft JH, van Schooten FJ, et al. Monitoring developmental toxicity in the embryonic stem cell test using differential gene expression of differentiation-related genes. Toxicol Sci 2010; 116: 130-9.

33 Dartel DAM, Penning JLA, Schooten FJ, Aldert H. Piersma AH. Transcriptomics-based identification of developmental toxicants through their interference with cardiomyocyte differentiation of embryonic stem cells. Toxicol Appl Pharmacol 2010; 243: 420-8.

34 Starkuviene V, Pepperkok R. The potential of high-content highthroughput microscopy in drug discovery. Br J Pharmacol 2007; 152: 62-71.

35 Barbaric I, Gokhale PJ, Jones M, Glen A, Baker D, Andrews PW. Novel regulators of stem cell fates identified by a multivariate phenotype screen of small compounds on human embryonic stem cell colonies. Stem Cell Res 2010; 5: 104-19.

36 Noggle SA, James D, Brivanlou AH. A molecular basis for human embryonic stem cell pluripotency. Stem Cell Rev 2005; 111-8.

37 Chen WLK, Likhitpanichkul M, Ho A, Simmons CA. Integration of statistical modeling and high-content microscopy to systematically investigate cell-substrate interactions. Biomaterials 2010; 31: 248997.

38 McNeish J, Roach M, Hambor J, Mather RJ, Weibley L, Lazzaro J. et al. High-throughput screening in embryonic stem cell-derived neurons identifies potentiators of alpha-amino-3-hydroxyl-5-methyl4-isoxazolepropionate-type glutamate receptors. J Biol Chem 2010; 285: $17209-27$.

39 Ichida JK, Blanchard J, Lam K, Son EY, Chung JE, Egli D, et al. A small-molecule inhibitor of Tgf-beta signaling replaces Sox2 in reprogramming by inducing nanog. Cell Stem Cell 2009; 5: 491-503.

40 Elkabetz Y, Studer L. Human ESC-derived neural rosettes and neural stem cell progression. Cold Spring Harb Symp Quant Biol 2008; 73 : 377-87.

41 Louisse J, Bai Y, Verwei M, Sandt JJMV, Blaauboer BJ, Rietjens IM. Decrease of intracellular $\mathrm{pH}$ as possible mechanism of embryotoxicity of glycol ether alkoxyacetic acid metabolites. Toxicol Appl Pharmacol 2010; 245: 236-43.

42 Ogawa S, Tagawa Y, Kamiyoshi A, Suzuki A, Nakayama J, Hashikura Y, et al. Crucial roles of mesodermal cell lineages in a murine embryonic stem cell-derived in vitro liver organogenesis system. Stem Cells 2005; 23: 903-13.

43 Sakurai K, Shimoji M, Tahimic CGT, Aiba K, Kawase E, Hashikura Y.et al. Efficient integration of transgenes into a defined locus in human embryonic stem cells. Nucleic Acids Res 2010; 38: e96.

44 Ebert AD, Svendsen $C N$. Human stem cells and drug screening: opportunities and challenges. Nat Rev Drug Discov 2010; 9: 1-6.

45 Desbordes SC, Placantonakis DG, Ciro A, Socci ND, Lee G, Djaballah $\mathrm{H}$, et al. High-throughput screening assay for the identification of compounds regulating self-renewal and differentiation in human embryonic stem cells. Cell Stem Cell 2008; 2: 602-12.

46 Zanella F, Lorens JB, Link W. High content screening: seeing is believing. Trends Biotechnol 2010;28:237-45.

47 Williamson AJ, Smith DL, Blinco D, Unwin RD, Pearson S, Wilson C, et al. Quantitative proteomics analysis demonstrates posttranscriptional regulation of embryonic stem cell differentiation to hematopoiesis. Mol Cell Proteomics 2008; 7: 459-72.

48 Yocum AK, Gratsch TE, Leff N, StrahlerJR, Hunter CL, Walker AK, et al. Coupled global and targeted proteomics of human embryonic stem cells during induced differentiation. Mol Cell Proteomics 2008; 7: 
750-67.

49 Bondue A, Lapouge G, Paulissen C, Semeraro C, lacovino M, Kyba M, et al. Mesp1 acts as a master regulator of multipotent cardiovascular progenitor specification. Cell Stem Cell 2008; 3: 69-84.

50 Uibel F, Mühleisen A, Köhle C, Weimer M, Stummann TC, Bremer S. A new stem cell-based reporter assay aimed to predict embryotoxic potential of drugs and chemicals. Reprod Toxicol 2010; 30: 103-12.

51 Cao T, Lu K, Fu X, Heng BC. Differentiated fibroblastic progenies of human embryonic stem cells for toxicology screening. Cloning Stem Cells 2008; 10: 1-9.

52 Buesen R, Genschow E, Slawik B, Visan A, Spielmann H, Luch A, et al. Embryonic stem cell test remastered: comparison between the validated EST and the new molecular FACS-EST for assessing developmental toxicity in vitro. Toxicol Sci 2009; 108: 389-400.

53 Festag M, Viertel B, Steinberg P, Sehner C. An in vitro embryotoxicity assay based on the disturbance of the differentiation of murine embryonic stem cells into endothelial cells. II. Testing of compounds. Toxicol in Vitro 2007; 21: 1631-40.

54 Harrill JA, Freudenrich TM, Machacek DW, Stice SL, Mundy WR. Quantitative assessment of neurite outgrowth in human embryonic stem cell-derived hN2TM cells using automated high-content image analysis. Neurotoxicology 2010; 31: 277-90.

55 Theunissena PT, Schulpen SHW, Dartela DAMV, Hermsen SAB, Schooten SJV, Piersma AH. An abbreviated protocol for multilineage neural differentiation of murine embryonic stem cells and its perturbation by methyl mercury. Reprod Toxicol 2010; 29: 383-92.

56 Kulkarni JS, Khanna A. Functional hepatocyte-like cells derived from mouse embryonic stem cells: a novel in vitro hepatotoxicity model for drug screening. Toxicol in Vitro 2006; 20: 1014-22.

57 Prestwich GD. Evaluating drug efficacy and toxicology in three dimensions: using synthetic extracellular matrices in drug discovery. Accounts Chem Res 2008; 41: 139-48.

58 Pan G, Thomson JA. Nanog and transcriptional networks in embryonic stem cell pluripotency. Cell Res 2007; 17: 42-9.

59 Babaie Y, Herwig R, Greber B, Brink TC, Wruck W, Groth D, et al. Analysis of Oct4-dependent transcriptional networks regulating selfrenewal and pluripotency in human embryonic stem cells. Stem Cells 2007; 25: 500-10.

60 Roel Nusse. Wnt signaling and stem cell control. Cell Res 2008; 18 : 523-7.

61 Kochegarov A. Small molecules for stem cells. Expert Opin Ther Pat 2009; 19: 275-81.

62 Jensen J, Hyllner J, Björquist P. Human embryonic stem cell technologies and drug discovery. J Cell Physiol 2009; 219: 513-9.

63 Tenzen T, Zembowicz F, Cowan CA. Genome modification in human embryonic stem cells. J Cell Physiol 2010; 222: 278-81. 